\title{
Apropiación y uso del territorio en la colonización campesina en el suroccidente del departamento de Cundinamarca
} en la segunda mitad del siglo XIX'

Sonia Alejandra Caicedo Vargas ${ }^{2}$
Universidad Autónoma de Colombia

Artículo de Investigación

Recibido: abril 14 de 2015 - Aprobado mayo 27 de 2015

\section{Resumen}

El presente artículo expone de manera concisa el resultado de una investigación monográfica cuyo problema de investigación fue cómo los campesinos colonos se relacionaron con el territorio en la colonización campesina en el Suroccidente del departamento de Cundinamarca en la segunda mitad del siglo XIX. A partir del análisis de esta relación en términos de apropiación y uso del territorio, se identificó y describió, en primer lugar, cómo estaba constituido el territorio del Suroccidente del departamento de Cundinamarca en el periodo mencionado, desde la configuración políticoadministrativa y de los dos principales caminos que articularon la región; y en segundo lugar, los mecanismos por los cuales los campesinos colonos se apropiaron y usaron el territorio.

Palabras clave: Uso, apropiación, territorio, región, campesino colono, colonización

I El presente artículo de investigación es una síntesis del trabajo de grado presentado para obtener el título de historiadora de la Universidad Autónoma de Colombia. La investigación inició en octubre del 2013 y finalizó en marzo del 2015.

2 Historiadora de la Universidad Autónoma de Colombia. Dirección electrónica: soniacaicedo66@gmail.com 


\title{
Appropriation and use of territory in the countrymen colonization of the southwestern region of the departament of Cundinamarca in the second half of the 19th century
}

\begin{abstract}
The current article presents in a concise manner the results of a monographic research in which the research problem was how colonizing countrypeople related to the territory in the peasant colonization of the southwestern region of the Departamento de Cundinamarca in the second half of the 19th Century. Based on the analysis of the relationship between appropriation and use of the territory, firstly the territory of the southwestern region of the Departamento de Cundinamarca was identified and described from the perspective of its social and political configuration, as well as from that of the main roads that articulated the region, and secondly, the mechanisms through which peasants got appropriated of the territory and the use they did of it were identified and described.
\end{abstract}

Key words: Use, appropriation, territory, region, colonizing peasant, colonization

\section{Apropriação e uso do território na colonização campesina no sul ocidente do departamento de Cundinamarca na segunda metade do século XIX}

\section{Resumo}

O presente artigo apresenta de maneira concisa o resultado de uma investigação monográfica, cujo problema de investigação foi como os camponeses colonos se relacionaram com o território na colonização camponesa no sul ocidente do departamento de Cundinamarca na segunda metade do século XIX. Partindo da análise desta relação, em termos de apropriação e uso do território, se identificou e descreveu, em primeiro lugar, como estava constituído o território do sul ocidente do Departamento de Cundinamarca no período mencionado, desde a configuração político-administrativa e dos principais caminhos que articularam a região; e, em segundo lugar, os mecanismos pelos quais os camponeses colonos se apropriaram e usaram o território.

Palavras chave: Uso, apropriação, território, região, camponês colono, colonização.

\section{Introducción}

Para abordar la investigación se partió del programa epistemológico que Paul Ricoeur presenta en su libro La memoria, la historia, el olvido ${ }^{3}$, el que se divide en tres fases metodológicas. La primera fase fue de carácter heurístico y se constituyó con fuentes del Archivo General de la Nación de Bogotá (sección

3 Ricoeur, Paul. La memoria, la historia, el olvido. Argentina: Fondo de Cultura Económica. 2000, pág. 177-37I 
República, fondo Ministerio de Industria, Departamento de Baldíos tomo IX, folios I 84 a 193 y tomo I, folios 102 a 124), fuentes legales constituidas por el aparato constitucional de la segunda mitad del siglo XIX y libros e informes, tanto de viajeros como de otros autores.

El contenido etnográfico de los relatos de los viajeros permitió identificar los principales elementos que constituyeron el Suroccidente del departamento de Cundinamarca en la segunda mitad del siglo XIX (población, vegetación, estado de los caminos, producción agrícola y ganadera, entre otros), fundamentales para identificar la relación que los campesinos colonos establecieron con el territorio. Así, tenemos un estado del arte compuesto por autores como Jesús Federico Cornelio Aguilar Un paseo en verano a Peñalisa, Girardot y La Pradera, Rufino Gutiérrez Monografias (t. I), John Potter Hamilton Viajes por el interior de las provincias de Colombia (informe), Alfred Hettner Viajes por los Andes colombianos (1882-1884), José Ismael Romero Descripción de los ferrocarriles de Colombia, Charles Stuart Cochrane Viajes por Colombia 1823 y 1824 , Medardo Rivas Trabajadores de tierra caliente y un informe de la Comisión Corográfica incluido en el texto Geografia fisica y política de la Confederación Granadina: antiguas provincias de Bogotá, Mariquita, Neiva y San Martin.

Otros autores consultados cuya obra es distinta a la de los viajeros fueron Guillermo Ancizar Samper, Aníbal Galindo, Emiro Kastos, Felipe Pérez y Salvador Camacho Roldán. De este último autor se consultaron cinco documentos que desde un enfoque sociológico permitieron comparar y profundizar la información de los relatos de los viajeros. Los documentos son Camino carretero al Magdalena, Escritos sobre economía y política, Escritos varios, Memorias y Notas de viaje (Colombia y Estados Unidos).

Los escritos de este autor fueron valiosos en la investigación porque manifiestan el ambiente político, económico y social de la época, más si se tiene en cuenta su papel como propietario de varias haciendas en Cundinamarca y como presidente de la Junta del Camino de Occidente, ya que para él, el mejoramiento de las condiciones de tránsito impulsarían la explotación económica del país, base del pensamiento federalista. Este pensamiento fue fundamental a la hora de entender la dinámica exportadora de mediados del siglo XIX en el Suroccidente del departamento de Cundinamarca y el papel que jugó la hacienda y el campesino colono en ésta.

La segunda fase fue explicativa/comprensiva y se basó en la formulación de preguntas o hipótesis que guiaron el proceso de investigación (en la consulta de las fuentes). El mejor ejemplo para describir esta etapa se presentó cuando se hizo la revisión de varios documentos disponibles del fondo Ministerio de Industrias, Departamento de Baldíos en el Archivo General de la Nación de Bogotá. Así, en busca de resolver la hipótesis inicial ${ }^{5}$, se infirió, por un lado, que aquellos campesinos colonos

4 Adicionalmente, se consultó el Código Fiscal de los Estados Unidos de Colombia por el Congreso de 1873 y la Recopilación de las leyes y disposiciones vigentes sobre tierras baldías, como apoyo documental para contrastar (triangular) la información de las Constituciones.

5 La hipótesis inicial presuponía que durante esta época y en este territorio, se dinamizó la apertura de la frontera agraria por medio de la adjudicación estatal de tierras baldías, que no solo benefició a grandes propietarios, sino a campesinos sin tierra que, a su vez, construyeron formas específicas de apropiación y uso del territorio. 
que se describieron en esa hipótesis no figuraron como adjudicatarios en el Suroccidente del departamento de Cundinamarca para la segunda mitad del siglo XIX, como sí los hubo en otras regiones. Por ejemplo, en el Tolima se autodenominaron colonos y cultivadores de tierras baldías ${ }^{6}$; y por el otro, mediante la triangulación de este documento con fuentes como Economía y Nación de Salomón Kalmanovitz y El régimen agrario de la economía exportadora a la economía industrial de Jesús Antonio Bejarano, entre otros, se estableció que en el Suroccidente del departamento de Cundinamarca, para la segunda mitad del siglo XIX, al predominar la hacienda como unidad productiva, los campesinos colonos se integraron al proceso colonizador como arrendatarios en las haciendas.

Por último, la fase representativa comprendió la configuración del discurso histórico, que se presentó mediante la exposición de la intención historiadora. Es decir, los resultados de la investigación que se presentan en un trabajo escrito.

En el programa epistemológico propuesto por Paul Ricoeur, las tres fases deben ser entendidas como "momentos metodológicos imbricados entre sî" . De manera que, paralelo a la consulta de documentos de archivo y de acuerdo con las conclusiones que se fueron recopilando, el marco teórico y conceptual se fue reajustando.

Las discusiones historiográficas ${ }^{8}$ que se consultaron en torno al concepto de región, asumen su significado desde dos perspectivas complementarias. La primera lo da a entender como una unidad de análisis a nivel metodológico; y la segunda es de carácter funcional, en la medida que posibilita el estudio de fenómenos históricos, desde el punto de vista económico, político, social o cultural. Este concepto se asumió desde la posición de Marta Herrera, quien lo delimita como un "recurso metodológico que se define en función a la problemática estudiada"9.

Señala Marta Herrera en su libro Ordenar para controlar. Ordenamiento espacial y control político en las Llanuras del Caribe y en los Andes Centrales Neogranadinos. Siglo XVIII, que, para comprender el concepto de región es necesario precisar el de territorio, pues es en él, en el que se llevan a cabo

6 Cuando se llevó a cabo la búsqueda de fuentes en el Archivo General de la Nación, se evidenció la inexistencia de documentos que contemplaran adjudicaciones a los campesinos colonos de esta investigación. Sin embargo, cuando se hacía la revisión en el fondo Ministerio de Industria, Departamento de Baldíos se encontró una demanda en la que un grupo de 53 colonos y cultivadores de terrenos baldíos estaban siendo despojados de la tierra que el finado coronel Aurelino Pineda les había rentado hacía más de diez años, si no pagaban una suma mayor de cuatro pesos por cada hectárea de terreno. Para mayor información véase Archivo General de la Nación. Sección: República, Fondo Ministerio de Industria, Departamento de Baldíos, tomo XI, folios 184 a 193.

7 Ricoeur, Paul. Op.cit., pág. 177

8 Colmenares, Germán. La nación y la historia regional en los países andinos 1870-1930. (Material mimeografiado y publicado). Varios: selección de textos. Bogotá, Tercer Mundo, 1998. Cifuentes, Francisco. Introducción al estudio de los procesos culturales. En: Correa, Hernán Darío, Cuellar, Ricardo Alonso (editores). Imágenes y reflexión de la cultura en Colombia. Regiones, ciudades y violencia. Bogotá: Colcultura. 1991. Sevilla Casas, Elías. Procesos regionales en la periferia colombiana de oriente y occidente: aportes desde la historia y la antropología. Material mimeografiado. Herrera, Marta. Ordenar para controlar. Ordenamiento espacial y control político en las Llanuras del Caribe y en los Andes Centrales Neogranadinos. Siglo XVIII. Colombia: Academia Colombiana de la Historia, Instituto Colombiano de Antropología e Historia. 1999.

9 Herrera, Marta. Op.cit., pág. 22 
las acciones que permiten la construcción de una región ${ }^{10}$. Dicho así, el territorio se entendió como "una extensión terrestre delimitada que incluye una relación de poder, dominio y pertenencia, entre una porción o la totalidad del espacio geográfico"l y individuo o grupo social"'2.

El concepto de territorio, asumido desde la perspectiva de los geógrafos Gustavo Montañez Gómez y Ovidio Delgado Mahecha, posibilitó identificar la vinculación del concepto de región, a partir de la relación que se da entre el espacio geográfico y el sujeto o grupo social. Esta relación es determinada por la convergencia de factores culturales, económicos, político-administrativos, ideológicos, sociales, geográficos, históricos, de comunicación y demográficos, entre otros.

Todos estos factores, están vinculados con la territorialidad, en el sentido de cómo los sujetos o grupos sociales se apropian del territorio y hacen uso de sus recursos, en palabras de Gustavo Montañez Gómez, la territorialidad debe ser entendida como "el grado de dominio que tiene determinado sujeto o grupo social en cierto territorio (...), así como el conjunto de prácticas y sus expresiones materiales y simbólicas, capaces de garantizar la apropiación y permanencia de un territorio dado bajo determinado agente individual o social"'l3.

Considerando lo dicho con antelación, la apropiación del territorio es entendida como "el grado de posesión (tenencia) de una determinada porción de territorio por un individuo o grupo social"14 y el uso del territorio, como "el conjunto de prácticas que garantizan la apropiación por un individuo o grupo social"'l5.

Ahora bien, se asume el Suroccidente como una región por las dinámicas sociales que establecen su construcción y reconfiguración histórica de uso y apropiación. A grandes rasgos, las relaciones económicas comenzaron a perfilar la región desde antes de la llegada de los españoles, favorecidas por el intercambio de la producción de diversos pisos térmicos y las formas de organización social de la población que allí se ubicaba.

Los muiscas ocuparon las tierras frías y templadas, en una organización espacial concentrada en pequeñas aldeas y con centros ceremoniales y cacicazgos. Dentro de sus actividades económicas sobresale la agricultura (desarrollada en terrazas de cultivo), la producción textil y la producción de sal.

\section{Ibíd, pág. 26}

I Según Gustavo Montañez Gómez, el espacio geográfico se concibe como "una categoría social e histórica que abarca los procesos y resultados de la acumulación histórica de la producción, incorporación, integración y apropiación social de estructuras y relaciones espaciales en la biosfera terrestre". Montañez Gómez, Gustavo. Razón y pasión del espacio y el territorio. En: (Compilación). Espacio y territorio. Bogotá: Universidad Nacional de Colombia. 2001, pág. 17

12 Montañez Gómez, Gustavo- Delgado Mahecha, Ovidio. Espacio, territorio y región: conceptos básicos para un proyecto nacional. En: Cuadernos de Geografía, Revista del Departamento de Geografía de la Universidad Nacional de Colombia. Vol. VII, No I-2, 1998, pág. 123 lbíd., pág. 20.

13 Montañez Gómez, Gustavo. Razón y pasión del espacio y el territorio. Óp., cit., pág. 22

14 lbíd., pág. 124.

15 lbíd. 
Los panche ocuparon las tierras cálidas entre Villeta, Tibacuy y el río Magdalena. Eran comunidades heterogéneas en su desarrollo social, entre ellas se encuentran las tribus tocaimas, analaimas, siquemas, anapuimas, suitamas, síquimas, tocaremas, sasaimas, entre otras. Según los cronistas ${ }^{16}$, estas tribus eran crueles en la guerra y seminómadas, lo que nos permite inferir que su asentamiento territorial fue disperso. Entre sus actividades económicas se destacan la caza, la pesca, la producción de miel de abejas y la orfebrería.

Antes de la llegada de los españoles al actual territorio del Suroccidente del departamento de Cundinamarca, los muiscas habitaron en los actuales municipios de Facatativá, Madrid, Funza, Zipacón, Bojacá y Mosquera, y los panche, ocuparon los actuales municipios de Viotá, Apulo, Anapoima, El Colegio, La Mesa, San Antonio de Tequendama, Tena, Quipile, Anolaima, Jerusalén, Guataquí, Tocaima, Nariño, Agua de Dios, Girardot, Nilo y Ricaurte. Este territorio estuvo cruzado y conectado por una red de caminos que, además de permitir la circulación e intercambio de la producción agrícola, orfebre, minera y textil ${ }^{17}$; posibilitó la delimitación de las zonas de dominio y la frontera de paz o guerra entre estas comunidades; relaciones que serían desarticuladas con la llegada de los españoles.

La conquista española en los territorios muisca y panche fue distinta. Los panche fueron casi aniquilados (pese a su condición de guerreros) por el reducido número de su población. Los indígenas panche y muiscas que sobrevivieron, fueron sometidos a las instituciones económicas y sociales impuestas tras su derrota por los españoles, la Encomienda, la Mita y el Resguardo, ya fuese por el control de particulares o de las compañías religiosas que acompañaron la empresa conquistadora y colonizadora.

La conquista del Suroccidente de Cundinamarca, como se ha indicado, desarticuló las zonas de influencia y de control de las comunidades prehispánicas en el territorio. Así, se impuso una nueva lógica en cuando a la concentración de la fuerza de trabajo en pocas poblaciones y al control centralizado del territorio. Esta centralización privilegió las zonas altas de la altiplanicie de Cundinamarca, hizo énfasis en el control de las poblaciones de interés demográfico cercanas a SantaFe y asignó a gran parte del antiguo territorio panche la función de corredor vinculante entre SantaFe y el Río Magdalena. Al respecto, Martha Herrera señala que "el impacto de la conquista sobre las poblaciones indígenas tuvo así consecuencias duraderas, pues determinó durante mucho tiempo, a veces hasta nuestros días, el carácter de región"18.

Durante la Colonia el territorio del Suroccidente tendrá una dinámica económica en dos sentidos. El primero, como tránsito de mercancías y productos agrícolas de las tierras calientes a orillas del Magdalena por el camino que conduce a Honda; y el segundo, por la actividad comercial dinamizada a

I6 Fray Pedro Simón. Noticias Historiales de las conquistas de Tierra Firme en las Indias Occidentales. Tomo II. Bogotá: Casa Editorial de Medardo Rivas, I882-1892.

17 Groot, Ana María. Sal, caminos y mercaderes. El caso Muisca en el siglo XVI. En: Herrera, Leonor y Cardale de Schrimpff, Marianne (Eds.). Caminos precolombinos. Bogotá: Instituto Colombiano de Antropología e historia. Iª edición. 2000., pág. 75

18 Herrera, Martha. Op., Cit., pág. 30 
partir de las haciendas productivas y de recreación de destacados propietarios bogotanos. Por ejemplo, durante el siglo XVIII toman relevancia algunas haciendas por la siembra de caña, el establecimiento de trapiches o por ser el lugar de descanso de las elites bogotanas ${ }^{19}$.

Así, en la segunda mitad del siglo XIX las transformaciones presentes en el Suroccidente de Cundinamarca fueron el resultado de un proceso histórico, que configuró y reconfiguró la región. La convergencia de procesos económicos, sociales, institucionales y estructurales asignó a la región un lugar periférico con respecto a la capital virreinal o republicana.

Por su valor geográfico, económico y político, esta región fue fundamental para la elite bogotana. Posibilitó la conexión entre las tierras frías y las tierras calientes, vinculó el centro político del país con la vía principal para la época, el río Magdalena, y se posicionó como zona de expansión de la frontera agraria, que a diferencia de la región vallecaucana, no enfrentó en su desarrollo económico la crisis de la hacienda esclavista y su reconversión en haciendas productivas hacia el desarrollo capitalista.

La escasez y el mal estado de los caminos, que eran los caminos indígenas, apenas permitía la circulación de productos hacia y desde Bogotá. Esto hacía que la explotación o producción de otros productos como el café, el tabaco y el añil, entre otros, no fueran viables, dado que al no haber una demanda considerable de estos no era conveniente invertir en los grandes costos que requería su producción y transporte. Esta situación se modifica en la segunda mitad del siglo XIX, cuando la hacienda productiva destina su producción al mercado mundial.

La demanda de los productos que reclamaba el mercado mundial hizo que a la dinámica que se venía desarrollando en la región, se vinculara el fenómeno de colonización de tierras baldías, mediante una política de adjudicación impulsada por el Estado. Para el Suroccidente esta política se apoyó en la titulación de tierras a latifundistas (según los documentos disponibles consultados), para que establecieran haciendas que cultivaran los productos destinados al mercado mundial20. Lo anterior permite situar dentro de la tipología de colonización la del Suroccidente de Cundinamarca para el periodo estudiado como orientada o apoyada: "la colonización orientada o apoyada (...) cuenta con la acción del Estado en la creación y orientación de las condiciones económicas, en busca de un favorable asentamiento de las familias y una explotación más racional de los recursos naturales'”2!

19 Villegas, Jorge. La colonización de vertiente en el siglo XIX. Medellín: Centro de investigaciones económicas, Facultad de Ciencias Económicas, Universidad de Antioquia. 1977, pág. 55

20 Germán Colmenares, en "La formación de la economía colonial ( 1500 - I 740), indica cómo "el problema agrario en Colombia no se deriva así de una supuesta "herencia colonial", sino de la apertura de nuevas fronteras agrarias en el curso del siglo XIX. El examen del proceso muestra, por comparación, el agotamiento del sistema tradicional de las haciendas, incapaces de retener una mano de obra. Por esto no debe confundirse "latifundio improductivo" con "latifundio colonial". El latifundio colonial podía constituir una unidad productiva, la hacienda, dentro de las limitaciones impuestas por una tecnología rudimentaria, la escasez de mano de obra y la ausencia de capital. El latifundio improductivo posterior surgió de la concesiones de baldíos que se sustrajeron a la capacidad creativa de masas humanas desplazadas de las haciendas tradicionales". En: Ocampo Gaviria, José Antonio. Compilador. Historia económica de Colombia. Bogotá: Planeta. 2007, pág. 57

21 Instituto Geográfico "Agustín Codazzi”, Subdirección investigación y divulgación geográfica, división de investigaciones geográficas sección de Estudio en áreas no polarizadas. Situación y análisis del proceso colonizador en Colombia. Bogotá: Ministerio de Hacienda y Crédito público, IGAC. 1986, pág. 21 
Fue así como factores como la colonización, intensificada por la adjudicación de tierras baldías, hicieron que la hacienda del siglo XIX prestara mayor atención a la producción de café, tabaco y añil con fines exportables. Sin embargo, como ya se indicó, para ello se debía invertir, por ejemplo, en el mejoramiento y la construcción de las vías de comunicación. Entonces, con la política de adjudicación de tierras baldías para construcción de obras públicas, los antiguos caminos indígenas o de herradura poco a poco fueron optimizando sus condiciones físicas para su tránsito, ejemplo de ello es el desarrollo del camino de Occidente y La Mesa.

La fuerza de trabajo empleada en estas haciendas era jornalera (los jornaleros ubicaban sus parcelas entre las montañas y en época de cosecha prestaban su mano de obra para complementar sus ingresos), de paso (estaba constituida por habitantes de otras regiones, que ofrecían sus servicios en época de cosechas) y arrendataria (formada por sujetos que a cambio de establecer una parcela dentro de la hacienda prestaban su fuerza de trabajo como forma de pago del arriendo) ${ }^{22}$. Los arrendatarios son los llamados campesinos colonos en la investigación.

Se infiere, pues la información disponible consultada no lo constata, que esta fuerza de trabajo era de la región o provenían de Bogotá. Los desplazamientos de los habitantes de una región a otra van a ser constantes a lo largo del siglo XIX, más si se tiene en cuenta que en ello intervinieron factores políticos, culturales y económicos como la búsqueda de una estabilidad (por las constantes guerras civiles) en las condiciones de vida.

\section{El Suroccidente del departamento de Cundinamarca en la segunda mitad del siglo $X I X$}

Al asumir el territorio que comprende el Suroccidente del departamento de Cundinamarca como una región, se evidencia cómo desde la época prehispánica y hasta la segunda mitad del siglo XIX se configuró y reconfiguró constantemente. Esta dinámica estuvo determinada por su posición frente a la capital, ya que la riqueza de su territorio la hizo una fuente económica para las élites bogotanas, representantes de una ideología basada en el interés económico. Por tanto, para entender con más precisión cómo estaba constituido el Suroccidente del departamento de Cundinamarca en la segunda mitad del siglo XIX, es importante tomar su configuración político administrativa desde los proyectos de ordenamiento territorial asumidos por las tendencias de la época: el centralismo y federalismo ${ }^{23}$, dado que esta respondió al pensamiento político de ambas tendencias, y por tanto permitieron que se dieran las condiciones para el desarrollo de factores políticos, económicos, sociales y culturales fundamentales en la construcción de la región.

22 Al mencionar las formas de trabajo dentro de la hacienda Marco Palacios define el sistema de arrendamiento como "un contrato bilateral por medio del cual el arrendatario arrendaba una estancia o parcela en la cual podía levantar una choza y cultivar lo que quisiera excepto "mata raizal" como el café". Véase Palacios, Marco. El café en Colombia 1850-1970, una historia económica, social y política. Bogotá: El Colegio de México, el Ancora editores. 1983, pág. 215

23 De 1855 a 1859 se crearon ocho de los Estados Soberanos de: Panamá (I 855), Antioquia (I 856), Cundinamarca (I 857), Boyacá, Santander, Bolívar, Magdalena y Cauca ( 859$)$. 
Una de las muchas manifestaciones del pensamiento político de ambas tendencias fue el aparato constitucional de la segunda mitad del siglo XIX. Así, la Constitución de la República de la Nueva Granada de 1843 es una continuidad del pensamiento centralista que venía rigiendo desde la primera Constitución. Como el eje principal de su pensamiento fue el de mantener la administración del gobierno unificada, para mantener el control fragmentó políticamente el territorio colombiano en unidades territoriales llamadas provincias ${ }^{24}$.

Por su carácter centralista, esta reforma constitucional no llevó a cabo modificaciones profundas en el ordenamiento territorial del Suroccidente del departamento de Cundinamarca en el periodo estudiado -como si lo van a hacer las constituciones federalistas-.

Para 1853, la reforma constitucional empezó a sentar las bases para el establecimiento del federalismo, el cual buscaba solucionar el problema de la unidad estatal (que regía el pensamiento de los centralistas) respetando y reconociendo la autonomía territoria ${ }^{25}$ de los Estados Soberanos. Para mantener la unidad estatal y la autonomía territorial, a lo largo de sus gobiernos desarrollaron reformas como la liberación socioeconómica del orden colonial mediante la abolición de las tierras comunales y la construcción de obras públicas como caminos, carreteras y ferrocarriles ${ }^{26}$, entre otras.

Todas estas reformas, vistas como "la expresión de la consolidación de los intereses de las oligarquías regionales" 27 , se evidencian en el ordenamiento territorial del Suroccidente del departamento de Cundinamarca en la segunda mitad del siglo XIX, dado que les permitieron ejercer un dominio sobre el territorio mediante la posesión de la tierra, en palabras de Frank Safford:

Estas reformas son la expresión del empeño de las oligarquías regionales por lograr un modelo socioeconómico liberal individualista. Se considera que estos cambios harían posible una movilización en el mercado libre de la tierra, de la mano de obra y de los recursos de capital, que beneficiara en gran parte el desarrollo de las industrias de exportación. El fraccionamiento de las tierras comunales indígenas, por ejemplo, debería, según lo esperado, movilizar tanto la tierra como la mano de obra $^{28}$.

Por ejemplo, la iniciativa por mejorar las condiciones de tránsito, efectuadas por los hacendados (beneficiados por la política de adjudicación para la apertura de caminos), se observa en la evolución de la construcción del camino de Occidente. En 1847 se inician las obras bajo la supervisión de los señores Rufino Cuervo, Luis Silvestre, Alfonso Acevedo y los hermanos Evaristo y Alejo Latorre.

24 Constitución de la República de Nueva Granada de 1843. [En línea]. Disponible en Alcaldía Mayor de Bogotá http://www. alcaldiabogota.gov.co/sisjur/normas/Normal.jsp?i=13695

25 Ocampo López, Javier. El Federalismo y la hegemonía liberal. En: Historia de Colombia, t 6. Bogotá: Salvat. 1990, pág. I32I

26 lbíd, pág. 54

27 Safford, Frank. Acerca de las interpretaciones socioeconómicas de la política en la Colombia del siglo XIX. Variaciones sobre un tema. En: Anuario Colombiano de Historia Social y de la Cultura, volumen I3-14. Pág. 163

28 Ibíd, pág. 94 
Posteriormente, en I854, el secretario de mejoras internas, Victoriano Paredes culminó la obra hasta Facatativá.

La construcción del camino de Occidente demuestra la importancia que los hacendados dieron al mejoramiento de las vías y que no es otra cosa que la expresión de su orientación política, pues personajes como Cuervo, Rufino, Acevedo y los Latorres fueron federalistas. Y como una de las reformas asumidas por esta tendencia consistió en el fortalecimiento de la economía nacional con fines exportadores, los hacendados invirtieron en la construcción y el mejoramiento de las vías de comunicación.

Los alcances de la autonomía regional que impulsaron los federalistas, se manifiestan en la Constitución del recién creado Estado ${ }^{29}$ de Cundinamarca en 1857, la que modificó las unidades territoriales, y por ende el ordenamiento territorial del Estado. Así, haciendo uso de su autonomía regional señaló "el territorio del Estado se dividirá (...) en departamentos, los departamento en distritos"30, y "las cabeceras de los distritos en ciudades, villas, parroquias y aldeas"3!.

La trascendencia de estas autonomías es visible cuando en 1857 el Estado de Cundinamarca integró departamentos que territorialmente no se ubicaban en el Suroccidente, pero que dependían o estaban administrativamente integrados a él. Me refiero específicamente, a los departamentos de Honda, Mariquita, Neiva, Purificación y el Guamo, localizados en el Tolima. Así, por ejemplo, el departamento de Mariquita, que se ubicó en el territorio del Tolima, integró los distritos suroccidentales de Guataquí y Nariño; y el departamento del Guamo, también en el Tolima, integró a Tocaima, Girardot, Nilo y Peñalisa, que desde ese momento se denominó Ricaurte.

Pero, además de que la dinámica anterior hace evidente el ordenamiento territorial al que estuvo sometido el Suroccidente del departamento de Cundinamarca para el periodo estudiado, ¿qué propósito específico del federalismo impulsaba? Es una manifestación de los intereses de los hacendados regionales, pertenecientes a esta tendencia, por extender su dominio territorial y beneficiarse económicamente de los procesos productivos de otras regiones, como, por ejemplo, la economía tabacalera del Tolima.

La dinámica de integración de departamentos no involucró únicamente al Tolima, sino también a Bogotá (capital del Estado de Cundinamarca). Por ejemplo, Bogotá, que se ubicaba en el centro de Cundinamarca, fue dividido en el $1{ }^{\circ}$ departamento de Bogotá formado por los distritos suroccidentales de Viotá, El Colegio y San Antonio, y en el $2^{\circ}$ departamento de Bogotá conformado por Facatativá, Serrezuela, Funza, Bojacá, Quipile, Anapoima, La Mesa, Tena, Anolaima y Zipacón. Posteriormente, en 1860, los dos departamentos de Bogotá se unifican.

Por lo anterior, se infiere que, contrario al Tolima, la dinámica de Bogotá respondió a la necesi-

29 Cada Estado estaba en el derecho de establecer su propia Constitución, la cual se originaba después de una guerra civil.

30 Constitución Política del Estado de Cundinamarca 1857, art. 3 [En línea]. Disponible en Biblioteca Virtual Colombiana Universidad Nacional de Colombia www.bdigital.unal.edu.co/6938/

31 Ibíd. Art. 72. 
dad de los federalistas por mantener el contacto con la capital, todo en beneficio de sus propósitos. Pues, asuntos como las relaciones exteriores y el comercio exterior ${ }^{32}$, que eran fundamentales para llevar a cabo sus intenciones económicas, recaían en la administración del gobierno central, situado en Bogotá.

Esta línea de argumentación nos lleva a aclarar el siguiente cuestionamiento. Desde la creación del Estado de Cundinamarca, este tuvo tres capitales Bogotá, Funza y Zipaquirá. Entonces ¿Por qué no hubo integración de departamentos en los dos últimos? Basados en la información consultada en el texto de Roberto Velandía Historia geopolítica de Cundinamarca, departamento-municipio-inspeccionesdepartamentos de policía, se concluye que Funza y Zipaquirá al ser las capitales del Estado por un año, 1863 y 1865 respectivamente, sus administraciones no influyeron profundamente. Pero, como Bogotá fue capital por veintisiete años, se debía asumir un ordenamiento territorial estratégico ${ }^{33}$. Como afirma Germán Colmenares:

[En el mundo andino -y en el Hispanoamericano en general- la centralidad de un lugar nunca surgió de intercambios espontáneos sino de privilegios de tipo político administrativo. (...). Qué sentido tienen, por ejemplo, los sucesivos acomodos o reacomodos constitucionales de provincias, departamentos, estados, cantones, municipios etc. sino a legitimar el ordenamiento político-territorial, (...) el que, la mayoría de las veces figuraba en el primer título de la Constitución $\left.{ }^{34}\right]$.

La autonomía territorial que obtuvo el Tolima al convertirse en Estado en 1861, le permitió revertir esta dinámica territorial (de integración). Por tanto, los departamentos de Neiva y Mariquita se agregaron a Tolima, mientras que al Estado de Cundinamarca se le agregaron otros dos departamentos que incorporaron los distritos que habían pertenecido a Neiva y Mariquita.

El Radicalismo u Olimpo Radical, que fue una orientación política del Federalismo, asumió plenamente el gobierno entre 1863 y 1878. Además de continuar con las reformas propuestas desde la década de los cincuenta, se propuso orientarlas hacia el fortalecimiento de la economía nacional con miras a crear las condiciones para integrar al país en el mercado exportador, bajo los modelos de Gran Bretaña, Estados Unidos y Francia, entre otros ${ }^{35}$. Estas medidas se sustentaron en la Constitución Política de los Estados Unidos de Colombia de 1863.

32 Según Jorge Orlando Melo, el gobierno central administraba las relaciones exteriores, el crédito público, el ejército nacional, el comercio exterior, los sistemas monetarios y el fomento de las vías interoceánicas; mientras los Estados Federales podían intervenir en la instrucción pública, los correos, la estadística y el manejo de los territorios indígenas. Véase Melo, Jorge Orlando. Del federalismo a la Constitución de 1886. En: Nueva Historia de Colombia, t I. Bogotá: Planeta. 1989., págs. 18-19

33 Velandía, Roberto. Historia geopolítica de Cundinamarca, departamento-municipio-inspecciones-departamentos de policía. Bogotá: Imprenta Departamental Antonio Nariño 197I, pág. 67.

34 Colmenares, Germán. La nación y la historia regional en los países andinos 1870-1930. Op. Cit., pág. 10.

35 Ocampo López, Javier. El Federalismo y la hegemonía liberal. Op. Cit., pág. 1317. 
Esta reforma constitucional, además de continuar con la confederación perpetua de los Estados Soberanos de Antioquia, Bolívar, Boyacá, Cauca, Cundinamarca, Magdalena, Panamá y Santander6, incorporó el recién creado Estado Soberano del Tolima.

La variabilidad del ordenamiento territorial de los municipios que integran el Suroccidente desde el federalismo va a continuar hasta I886, cuando el centralismo asume nuevamente la administración del país.

La reforma constitucional de 1886 estableció nuevamente el centralismo. Contrario al centralismo de antes de 1843, el de este periodo se volvió más autoritario. Todas las autoridades dependieron del presidente, se amplió el poder de la Iglesia, los derechos individuales se limitaron y "ien lo económico? Frenó a las oligarquías regionales ${ }^{37 \text { " }}$ para aumentar los ingresos del Estado. Aunque, no por ello, se dejó de prestar atención al mejoramiento de la infraestructura, entre otros.

En cuanto al ordenamiento territorial los Estados perdieron su autonomía y quedaron sujetos al Estado como departamentos, razón por la cual se debía asumir un nuevo orden territorial (en el siglo $X X)$ que diera continuidad con el desarrollo de los propósitos de las tendencias centralista y federalista.

\section{Apropiación y uso del territorio por parte de los campesinos colonos}

Como se ha evidenciado hasta el momento, en el siglo XIX, después de las guerras de independencia, el Estado colombiano entre muchos otros propósitos, planteó el de promover el crecimiento económico del campo a través del fortalecimiento del mercado interno. Esto se podía lograr si el país ampliaba el rango de su producción a la demanda del mercado exterior, esto en razón de que el desarrollo económico del país dependería ante todo del comercio internacional ${ }^{38}$.

Por tal motivo, las exportaciones que se venían haciendo desde la Colonia, ya no podían quedarse en la producción de artículos básicos (maíz, papa, plátano, entre otros) u oro, ahora se debía producir en pro de "una expansión real del sector exportador 39 ", incluyendo productos como el tabaco, el añil, la quina y el café.

La participación del Estado en la producción de productos exportables no fue económicamente significativa pues, después del financiamiento de la guerra de independencia y las constantes guerras civiles del siglo XIX, sus recursos eran limitados para asumir dicha empresa. Fue así como sabiendo

36 Constitución Política de los Estados Unidos de Colombia de 1863. Capítulo I, art. I [En línea]. Disponible en Alcaldía Mayor de Bogotá http://www.alcaldiabogota.gov.co/sisjur/normas/Normal.jsp?i=13698\#0

37 Melo, Jorge Orlando. Del federalismo a la Constitución de 1886. Op. Cit., pág. 89.

38 Melo, Jorge Orlando. Las vicisitudes del modelo liberal ( I 850- I 899). En: Ocampo, José Antonio (compilador). Historia económica de Colombia. Bogotá: Planeta, Fedesarrollo. 2007, pág. 165

39 Ocampo, José Antonio. Colombia y la economía mundial 1830-1910. Santafé de Bogotá: Tercer Mundo, Fedesarrollo, Colciencias. 1998, pág. 65 
que uno de sus bienes, las tierras baldías ${ }^{40}$, era fundamental para la explotación de estos artículos, decidió impulsar su ocupación, mediante una política de adjudicación ${ }^{41}$. Asumido esto, el Estado aumentaría sus ingresos y activaría la economía del país.

Esta política de adjudicación consistía en la titulación, por parte del Estado, de un globo de tierra para explotarla. En el Suroccidente del departamento de Cundinamarca, para la segunda mitad del siglo XIX, se hizo con base en la titulación a grandes latifundistas. Por medio de bonos y vales redimibles el latifundista reclamaba una porción de globo de tierra para explotarla.

Esta explotación no solo fue dirigida a la actividad agropecuaria, otras finalidades fueron la construcción de obras públicas tal y como lo fueron los caminos de Occidente y La Mesa, la creación de nuevas poblaciones o la anexión de nuevas tierras a ellas y la colonización.

La explotación que debían hacer los latifundistas, que era a lo que estaba orientada la política, debía hacerse con base en el fortalecimiento de la economía nacional. Esto explica por qué los federalistas y en menor medida los centralistas, llevaron a cabo reformas, por ejemplo, tendientes a eliminar las tierras comunales. Eliminando las tierras comunales, se podía fomentar la construcción de obras, el desarrollo de unidades productivas bajo la racionalidad capitalista, la producción y explotación de productos exportables y la colonización, entre otros. En términos de Marcelo Carmagnani:

La inserción de las economías latinoamericanas en la economía mundial (...) no dependía solamente de la mayor capacidad de las oligarquías para ajustarse a la demanda internacional mediante el incremento de la oferta y, por tanto, de la producción de bienes exportables. También dependía de la posibilidad de desarrollar las raquíticas estructuras comerciales existentes, los ferrocarriles y los puertos ${ }^{42}$.

La dinámica anterior, sobre la política de adjudicación, nos permite indicar que los campesinos colonos, al no beneficiarse de la adjudicación, no tuvieron los derechos de propiedad sobre sus parcelas, por tanto su apropiación solo fue por la tenencia de la tierra. Lo que significaba formalmente poseer sólo los derechos sobre su uso.

40 Según el diccionario de la Real Academia española el termino baldío hace referencia a "la tierra que ni esta labrada ni adehesada" [En línea]. Disponible en diccionario de la Real Academia Española www.http://lema.rae.es/drae/?val=baldio. Así mismo, según el Libro I, artículo 878 del Código Fiscal de los Estados Unidos de Colombia de 1873 se consideran tierras baldías y de propiedad de la Nación: "las tierras incultas (que no están apropiadas con títulos legítimos) situadas en los territorios que administra la Nación, los márgenes de los ríos navegables no apropiadas a particulares con título legítimo, las costas desiertas de la República, las islas del río o mar, dentro de la jurisdicción de ésta que no están ocupadas por poblaciones organizadas con justo título a las tierras incultas de las cordilleras y valles." Código Fiscal de los Estados Unidos de Colombia sancionado por el Congreso de 1873. Bogotá: Imprenta de Vapor de Zalamea Hermano. I 882. [En línea]. Disponible en George a Smathers Libraries University of Florida, digital collections http://ufdc.edu/UF00085990/0000I/205j.

4 Salomón Kalmanovitz advierte que a partir de 1843 el otorgamiento de baldíos se hizo de forma acelerada y privilegiando a grandes empresarios. Véase Kalmanovitz, Salomón. Economía y nación, una breve historia de Colombia. Santafé de Bogotá: Tercer Mundo editores. 199, pág. 107

42 Carmagnani, Marcelo. Estado y sociedad en América Latina 1850-1930. Barcelona: Critica. 1984., pág. 108 
Esta tenencia de la tierra por parte de los campesinos colonos dependió del desarrollo de la hacienda -como unidad productiva primaria en el desarrollo de la economía nacional y exportadora-, pues como se verá más adelante y contrario a los derechos de uso que establecía la tenencia de la tierra, la hacienda determinó el uso que los campesinos colonos hacían del territorio. De ahí que para entender las dinámicas de apropiación y uso, los campesinos colonos se deben ubicar dentro de la hacienda, que era donde se desenvolvían, como arrendatarios.

La hacienda era la unidad productiva de mayor escala por ser propiedad de los latifundistas que eran el actor dominante en la región, por ser beneficiarios de la política de colonización y poseer el capital necesario para asumir la producción exportadora y la actualización técnica de las haciendas. Muchos de estos hacendados representaban los intereses políticos de las ya mencionadas tendencias centralista y federalista, por lo cual sus bases ideológicas constituían un factor fundamental en el desarrollo económico de sus haciendas. Tenemos el caso de Salvador Camacho Roldan, quien fuera poseedor de la hacienda Utica entre los municipios de Viotá y Tocaima

La fuerza de trabajo dentro de la hacienda estaba representada por jornaleros, trabajadores de paso, y, en mayor medida, arrendatarios. Valga aclarar que el número de trabajadores, con las fuentes consultadas para esta investigación, no pudo ser estimado cuantitativamente.

Los arrendatarios o campesinos colonos, prestaban sus servicios en la hacienda como forma de pago del arriendo ${ }^{43}$. Para cumplir con este pago prestaban servicios de ordeño, vaquería, en la siembra, recolección y preparación de cultivos, como capitanes de cuadrilla y mayordomos. Según Salomón Kalmanovitz, estas dos últimas labores se ganaban por la actitud de lealtad y sumisión que los campesinos demostraran ante los empresarios, quienes a su vez "les daban el derecho de mantener ganado y lotes para cosecha, y sus hijos tenían jornales asegurados" 44 .

Lo anterior nos permite analizar desde el punto de vista sociopolítico el interés que los hacendados tenían por mantener la lealtad de los arrendatarios, con fines políticos. Incentivos como el mejoramiento de sus condiciones económicas, llevaron a que los mayordomos y capitanes de cuadrilla -como intermediarios entre los hacendados y los demás arrendatarios- estimularan el caudillismo por medio de la prestación de sus servicios con fines militares ${ }^{45}$ (por ejemplo, en la guerra de I85।, en el gobierno de Hilario López).

Cuando los arrendatarios no trabajaban en sus sementeras -las que se ubicaban en sus parcelas- lo hacían en las de la hacienda ${ }^{46}$, cultivando productos básicos como maíz, papa, plátano y yuca, entre otros, y productos estratégicos destinados al mercado exterior, tales como el café, el tabaco y el añil.

Es importante indicar que en las sementeras de los campesinos colonos no se cultivaban productos

43 Bejarano, Jesús Antonio. El régimen agrario de la economía exportadora a la economía industrial. Bogotá: La Carreta. 1979 , pág. 169

44 Kalmanovitz, Salomón. Op. Cit., págs. I40-I 42

45 Carmagnani, Marcelo. Op. Cit. pág. 146.

46 El trabajo de los campesinos colonos en los cultivos de la hacienda variaba por el ciclo de producción, así, mientras un cultivo germinaba, en otra área de cultivo se recogía la cosecha o se iniciaba con el cultivo. 
exportables, porque los hacendados les prohibían hacerlo ${ }^{47}$. Primero, porque dejarían de trabajar en los cultivos de la hacienda; segundo, tenderían a desarrollar confianza en sí mismos, suprimiendo su dependencia de la hacienda; y tercero, al pasar más tiempo en sus parcelas las mejorarían y podrían exigir los derechos que les daban las leyes sobre las mejoras a la tierra ${ }^{48}$. Esta prohibición permite identificar una contradicción en cuanto a los derechos de apropiación que los campesinos obtenían por la tenencia de la tierra. Si esta tenencia presuponía poder definir los usos sobre el territorio ¿Por qué los hacendados les prohibían cultivar productos exportables? Por estar la parcela dentro de la hacienda ¿los hacendados tenían derechos sobre la tenencia de esa tierra? Así lo resume Marcelo Carmagnani:

[El control que se ejercía sobre la mano de obra dentro del latifundio se inscribe en un cuadro más amplio de control social. Las descripciones del latifundio de este periodo existen, por lo que respecta a la fuerza de trabajo, elementos comunes a todas las zonas de América Latina. Uno de ellos consiste en que el latifundio, aun el más moderno, controla a su población interior menos mediante el salario que mediante mecanismos serviles, en los que conjugan represión y paternalismo ${ }^{49}$.

Es importante señalar para posibles investigaciones, que esta dinámica de prohibición explicaría las causas de los posteriores conflictos (finales del siglo XIX e inicios del siglo $X X$ ) entre campesinos colonos y latifundistas sobre la tenencia de la tierra a lo largo del país, observables en el Suroccidente del departamento de Cundinamarca, en municipios como Viotá y Jerusalén.

Pero, si el control sobre la producción de los artículos que reclamaba el mercado exterior era tan marcado ¿qué nos dice la evolución de estos productos sobre los usos ejercidos por los campesinos colonos sobre el territorio?

En la producción de tabaco las prácticas que conllevaron al uso de los campesinos colonos sobre este producto, se hacen notorios en el proceso de siembra, recolección y preparación. Así, cuando estaba listo los campesinos colonos debían recoger rápidamente las hojas para evitar la aparición de hongos o manchas ${ }^{50}$. Luego las trasladaban a los caneyes, donde las secaban, aliñaban y planchaban para empacarlas en $z_{u r r o n e s^{51}}$ que eran elaborados con el cuero que suministraba el ganado.

47 Bejarano, Jesús Antonio. Op. Cit., pág. 165.

48 La ley 6 I de 1874 y la ley 48 de 1882 fueron las principales leyes sobre mejoras que beneficiaron a los campesinos colonos. Para mayor información consultar Recopilación de las leyes y disposiciones vigentes sobre tierras baldías (edición oficial). Bogotá: Imprenta de Medardo Rivas. 1884. [En línea]. Disponible en Biblioteca virtual, Biblioteca Luis Ángel Arango http://banrepcultural.org/blaavirtual/ derecho/recopilacion-de-las-leyes; Código Fiscal de los Estados Unidos de Colombia sancionado por el Congreso de 1873. Óp. Cit.

49 Carmagnani, Marcelo. Op. Cit., págs. I37-138.

50 Sastoque, Edna Carolina. Tabaco, quina y añil en el siglo XIX: Bonanzas efimeras. En: Credencial Historia. N 255. 20II. [En línea]. Disponible en Biblioteca virtual, Biblioteca Luis Ángel Arango http://www.banrepcultural.org/blaavirtual/revistas/credencial/ marzo20 I I/tabaco-quina-anil-siglo-xix párrafo 5

5 I Según el diccionario de la Real Academia española el termino zurrón hace referencia a "la bolsa grande de pellejo, que regularmente usan los pastores para guardar y llevar su comida u otras cosas" [En línea]. Disponible en diccionario de la Real Academia Española http://lema.rae.es/drae/?val=zurrones 
Contrario al tabaco, donde su siembra, recolección y preparación dependía únicamente de los campesinos colonos, en el caso del añil se requería de un mayor número de trabajadores. Los hacendados recurrían a la contratación de jornaleros y trabajadores de paso ${ }^{52}$, que junto con los arrendatarios se encargaban de llevar a cabo los tres procesos de preparación de la planta: el primero, era desyerbar y opacar las matas, para lo cual se acudía a la presencia de jornaleros, trabajadores de paso y arrendatarios; el segundo era el corte del jiquelete ${ }^{53}$ para cuyo trabajo se necesitaba de jornaleros y arrendatarios, cuando los hacendados requerían la labor con urgencia contrataban a trabajadores de paso; y el tercero era la maceración, batición, decocción, prensado y precipitado; para cada proceso se utiliza la mano de obra de arrendatarios ${ }^{54}$.

Esta fragmentación del trabajo fue otra manifestación del control que los hacendados ejercían sobre los campesinos colonos, en términos de Marcelo Carmagnani, este "factor que revistió gran importancia para el control de la población incluida en el latifundio fue la gran fragmentación de la mano de obra, fragmentación que en principio obedecía a las necesidades de gestión del latifundio pero que adquirió también un significado social ${ }^{55}$ ". Este significado está presente, por ejemplo, en el ya mencionado caudillismo.

El desarrollo de la hacienda cafetera en el Suroccidente, a partir de I870, se desarrolló con base en la fragmentación de las haciendas que databan del siglo XVIII ${ }^{56}$. Este fue el caso de las haciendas El Neptuno, Calandaima y San Miguel de Amanta en Viotá y Mesa de yeguas en El Colegio (todas fundadas antes de 1860). En 1888 la primera se dividió en las haciendas cafeteras Los Olivos, Java, Argentina y Argelia; posteriormente Los Olivos se fragmentó en La Magdalena ( 1894), Costa Rica ( I89 I), Africana ( 1898 ) y Buenos Aires ( 1898 ); la segunda, en 1870 cedió terreno para fundar la hacienda Ceilan; la tercera, en 1869 fundó Florencia y en 1884 Liberia; y la cuarta, se dividió, en 1882 en Misiones y en 1892 en la Golconda.

Según Jorge Orlando Melo, "estas haciendas estaban dirigidas por un nuevo tipo de empresario rural y urbano más ilustrado que el terrateniente tradicional, partidario del progreso técnico, dispuesto a ensayar nuevos cultivos y nuevas formas de actividad productiva ${ }^{57 "}$. Es por esta nueva tecnificación que los campesinos colonos solo cosechaban y recolectaban la semilla dado que su preparación se

52 Según Miguel Samper, el número de trabajadores de paso que comúnmente se encontraban en las regiones no eran suficientes para la extracción del añil, por tanto se debían traer más trabajadores lo que suponía una mayor inversión, pues se debía pagar el desplazamiento y dos días extras mientras se aclimataban. Samper, Miguel. Selección de escritos. Bogotá: Editorial y litografía presencia. 1977, pág. 118

53 Según la Real Academia española el jiquelete es una "planta de la familia de las Papilionáceas, del mismo género que el añil [En línea]. Disponible Real Academia Española http://lema.rae.es/drae/?val=jiquelete

54 Alarcón, Francisco José y Arias Gustavo. La producción y comercialización del añil en Colombia I 850- I 880. En: Anuario Colombiano de Historia Social y de la Cultura. V I5. 1987. [En línea]. Disponible en Biblioteca virtual, Biblioteca Luis Ángel Arango http:// www.banrepcultural.org/blaavirtual/revistas/revanuario/ancolh I5/indice.htm, pág. 194-195

55 Carmagnani, Marcelo. Op. Cit., pág. 136.

56 Para más información véase Palacios, Marco. El café en Colombia. Op. Cit., pág. 169.

57 Melo, Jorge Orlando. La evolución económica de Colombia, 1830-1900. En Manual de Historia de Colombia. Bogotá: Instituto colombiano de Cultura. 1979, pág. 62. 
realizó con base en la especialización, la que se realizaba en establecimientos específicos para secar, despulpar, tostar, moler, empacar y comercializar, entre otros.

Las dinámicas de uso y apropiación en el marco de la hacienda demuestran cómo los campesinos colonos al no ser beneficiarios de la política de adjudicación, tuvieron que dar su fuerza de trabajo en forma de pago de arriendo de su parcela, la cual les daba el derecho sobre su tenencia. Sin embargo, este derecho fue coartado por los hacendados al definir los usos que los campesinos colonos debían hacer en sus parcelas. Por tanto, esta fuerza de trabajo dentro de la hacienda significó que los usos ejercidos por los campesinos colonos tendieran a la economía agrícola y ganadera.

\section{Conclusiones}

La relación que estableció el campesino colono en el proceso de apropiación y uso del territorio, en la colonización del Suroccidente del departamento de Cundinamarca en la segunda mitad del siglo XIX, permite entender las dinámicas que se forjaron en torno a los sujetos y el territorio.

El análisis y la descripción de la configuración político-administrativa del territorio del actual Suroccidente hizo comprender su variabilidad, la cual dependió de cuatro reformas constitucionales que establecieron cómo debía estar conformado el territorio para efectos administrativos, todo de acuerdo a las dos tendencias de ordenamiento territorial que pugnaron en la época, el centralismo y el federalismo.

Este ordenamiento territorial, utilizado por ambas tendencias demostró que a pesar de que su marco de gobernabilidad era distinto en cuanto a conservar un Estado centralizado o no, las dos mantuvieron una movilidad constante de las unidades territoriales. Esta condición puso de manifiesto que estas modificaciones obedecieron a un proyecto ideológico fundamentado en la necesidad y los intereses económicos de sus representantes, en su mayoría propietarios de haciendas, por vincularse al mercado externo, mediante la producción de artículos como el café, el tabaco y el añil.

Ahora bien, esta configuración político-administrativa también manifestó que, a pesar de su variabilidad, el Suroccidente del departamento de Cundinamarca durante la segunda mitad del siglo XIX siempre mantuvo su consolidación como región, hecho que se logró por la articulación de los caminos que la vincularon, el de Occidente y el de La Mesa.

El análisis de estos dos caminos (se describen detalladamente en la monografía) posibilitó identificar que la hacienda como propiedad latifundista, tuvo un papel fundamental en el desarrollo de la región. Esta propiedad para la segunda mitad del siglo XIX, tomó un gran impulso gracias a la política de adjudicación que el Estado fomento para el crecimiento de la economía con fines exportadores.

Esta adjudicación de tierras baldías se hizo a grandes latifundistas, no, según los documentos disponibles consultados, a campesinos colonos. Pero la no participación de esta política por parte 
de los campesinos colonos, no significó que no llevaran a cabo una apropiación del territorio, pues, estos lo hicieron sólo por la tenencia de la tierra de sus parcelas (como arrendatarios).

Lo anterior significó que la apropiación y los usos de los recursos que los campesinos colonos ejercieron sobre el territorio, se ubicaron dentro de la hacienda. Sin embargo, a pesar de que los campesinos colonos poseían la tenencia sobre su parcela, los usos ejercidos sobre ésta, siempre dependieron de la hacienda, ya fuera porque los mayordomos como intermediarios de los hacendados les dijeran qué debían y qué no debían cultivar en sus parcelas, o, porque a raíz de su condición tuvieran que estar obligados a realizar lo que les dijera el hacendado, baste mencionar el fenómeno del caudillismo.

Además, resulta claro que, para el Suroccidente del departamento de Cundinamarca, la relación establecida entre campesinos colonos y hacendados incuba una contradicción socioeconómica, que conlleva a asegurar que las formas de desarrollo de la hacienda en este territorio, giraron en torno a la producción para el mercado mundial bajo la racionalidad capitalista, mientras que las formas de contratación de la mano de obra, tuvieron una lenta actualización a este respecto, haciendo palpable una dinámica hacia la proletarización campesina. Contradicción que también se expresará como un conflicto social declarado en las luchas campesinas en las primeras décadas del siglo XX motivadas, en primer lugar, por el derecho a la tierra y el reconocimiento de la posesión y mejoras de sus parcelas. En segundo lugar, por la mejora de las condiciones de contratación o arreglos impuestos por los hacendados, y finalmente, por la ruptura de las formas de dominación política y social que hacían parte de la estructura de la hacienda, y cuya abolición no podía ser entendida independientemente de la lucha por la tierra, y viceversa" 58 .

Así, el caso del Suroccidente de Cundinamarca es un ejemplo de sustracción del campesino del reparto de tierras en el país. Las llamadas reformas agrarias que se han adelantado en el país no han logrado subsanar esta situación, que como bien lo señaló Germán Colmenares, no es producto de la herencia colonial, sino de la asignación latifundista que se hace en el siglo XIX, y que tiene proyección hasta el presente.

El predominio latifundista en el país muestra la vigencia de los estudios sobre la partición y asignación de tierras a campesinos; los estudios locales y regionales nutrirán tanto la perspectiva de análisis de los académicos, como también las del país, hacia la comprensión de una problemática aún actual. Por ejemplo, hoy en día la reactivación de la economía del campo sería fundamental para el país, porque representaría una fuente económica, que no solo beneficiaría a los grandes latifundistas, sino a los campesinos que no poseen el derecho de propiedad sobre las tierras que ocupan.

58 Sánchez, Gonzalo. Las ligas campesinas en Colombia. Bogotá: Ediciones Tiempo Presente. 1977, pág. 17 


\section{Fuentes documentales y bibliografía}

\section{Fuentes primarias}

Fuentes de archivo

Archivo General de la Nación. Sección: República, Fondo Ministerio de Industria, Departamento de Baldíos, tomo $\mathrm{Xl}$, folios 184 a 193

Fuentes legales

Código Fiscal de los Estados Unidos de Colombia sancionado por el Congreso de 1873. Bogotá: Imprenta de Vapor de Zalamea Hermano. 1882. [En línea]. Disponible en George a Smathers Libraries University of Florida, digital collections http://ufdc.edu/UF00085990/0000I/205j

Recopilación de las leyes y disposiciones vigentes sobre tierras baldías (edición oficial). Bogotá: Imprenta de Medardo Rivas. I884. [En línea]. Disponible en Biblioteca virtual, Biblioteca Luis Ángel Arango http://banrepcultural. org/blaavirtual/derecho/recopilacion-de-las-leyes

Constitución de la República de Nueva Granada de 1843. [En línea]. Disponible en Alcaldía Mayor de Bogotá http:/l www.alcaldiabogota.gov.co/sisjur/normas/Normal.jsp?i= 3695

Constitución de la República de Nueva Granada de 1853. [En línea]. Disponible en Alcaldía Mayor de Bogotá http:// wuw.alcaldiabogota.gov.co/sisjur/normas/Norma l.jsp?i=13696\#0

Constitución Política del Estado de Cundinamarca 1857 [En línea]. Disponible en Biblioteca Virtual Colombiana Universidad Nacional de Colombia www.bdigital.unal.edu.co/6938/

Constitución para la Confederación granadina de 1858. [En línea]. Disponible en Alcaldía Mayor de Bogotá http:// www.alcaldiabogota.gov.co/sisjur/normas/Norma l.jsp?i=13697\#0

Constitución Política de los Estados Unidos de Colombia de 1863. [En línea]. Disponible en Alcaldía Mayor de Bogotá http://www.alcaldiabogota.gov.co/sisjur/normas/Normal.jsp?i=13698\#0

Constitución Política de la República de Colombia de 1886 [En línea]. Disponible en Alcaldía Mayor de Bogotá http:/l www.alcaldiabogota.gov.co/sisjur/normas/Norma l.jsp?i=7। 53\#0

Libros e informes

Aguilar, Federico. Un paseo en verano a Peñalisa, Girardot y La Pradera. Bogotá: Imprenta de Ignacio Borda. I886. [En línea]. Disponible en Biblioteca virtual, Biblioteca Luis Ángel Arango http://www.banrepcultural.org/ blaavirtual/viajesydescripciones/un-paseo-en-verano-a-penalisa-girardot-y-la-pradera

Ancizar Samper, Guillermo. Contribución al estudio de una legislación de baldíos y de colonización en Colombia. Buenos Aires: (s.n). 19|4. [En línea]. Disponible en Biblioteca virtual, Biblioteca Luis Ángel Arango http:// www.banrepcultural.org/blaavirtual/derecho/contribucion-al-estudio-de-una-legislacion-de-baldios-y-decolonizacion-en-colombia 
Camacho Roldán, Salvador. Camino carretero al Magdalena. Bogotá: (s.n). I858. [En línea]. Disponible en Biblioteca virtual, Biblioteca Luis Ángel Arango http://www.banrepcultural.org/blaavirtual/transporte/camino-carreteroal-magdalena- I

Camacho Roldán, Salvador. Escritos varios. Bogotá: Incunables. 1983.

Camacho Roldán, Salvador. Escritos sobre economía y política. Bogotá: Instituto colombiano de cultura. 1976.

Camacho Roldán, Salvador. Memorias. Bogotá: Editorial Bedout. 1923.

Camacho Roldán, Salvador. Notas de viaje (Colombia y Estados Unidos). T I. Bogotá: Talleres Gráficos del Banco de la República. 1973.

Cochrane, Charles Stuart. Viajes por Colombia 1823 y 1824. Bogotá: Banco de la República. 1994.

Fray Pedro Simón. Noticias Historiales de las conquistas de Tierra Firme en las Indias Occidentales. Tomo II. Bogotá: Casa Editorial de Medardo Rivas, 1882 -1892.

Galindo, Anibal. Estudios económicos y fiscales. Bogotá: Sol y Luna. 1978.

Gutiérrez, Rufino. Monografias. Tomo I. Bogotá: Imprenta Nacional, Biblioteca de Historia nacional, V. XXVIII. 1920. [En línea]. Disponible en Biblioteca virtual, Biblioteca Luis Ángel Arango http://www.banrepcultural. org/blaavirtual/historia/uno/uno IOa.htm

Hamilton, John Potter. Viajes por el interior de las provincias de Colombia. Bogotá: Imprente del Banco de la República. 1995 [En línea]. Disponible en Biblioteca virtual, Biblioteca Luis Ángel Arango http://www.banrepcultural. org/blaavirtual/historia/viinpro/indice.htm

Hettner, Alfred. Viaje por los Andes colombianos ( 1882 - | 884). Bogotá: Talleres Gráficos del Banco de la República. 1976 [En línea]. Disponible en Biblioteca virtual, Biblioteca Luis Ángel Arangohttp://www.banrepcultural.org/ blaavirtual/historia/viaand/indice.htm

Holton, Isaac. La Nueva Granada: veinte meses en los Andes. Bogotá: Banco de la República. 198 I.

Kastos, Emiro. Artículos escogidos. V 31. Bogotá: Biblioteca Banco Popular. 1972.

Pérez, Felipe. Geografia fisica y política del Estado de Cundinamarca en la Nueva Granada. Bogotá: Imprenta del Estado de Cundinamarca. 186I. [En línea]. Disponible en Biblioteca virtual, Biblioteca Luis Ángel Arango http://www.banrepcultural.org/blaavirtual/geografia/jeografia-fisica-i-politica-del-estado-de-cundinamarca.

Pombo, Manuel. De Medellín a Bogotá. Bogotá: Tercer Mundo editores. 1992.

Rivas, Medardo. Trabajadores de tierra caliente. Bogotá: Incunables. 1983 (fecha de publicación 1899).

Romero, Ismael José. Descripción de los ferrocarriles de Colombia. Y un viaje por el río Magdalena para usos de escuelas y colegios, e itinerario para viajeros. Bogotá: Imprenta Eléctrica. 1906. [En línea]. Disponible en Biblioteca virtual, Biblioteca Luis Ángel Arango http://www.banrepcultural.org/blaavirtual/viajes-y-descripciones/descripcion-delos-ferrocarriles-de-colombia-y-viaje-por-el-rio-magdalena. 


\section{Fuentes secundarias}

Libros, artículos

Alarcón, Francisco José y Arias, Gustavo. La producción y comercialización del añil en Colombia 1850-1880. En: Anuario Colombiano de Historia Social y de la Cultura. V I5. 1987. [En línea]. Disponible en Biblioteca virtual, Biblioteca Luis Ángel Arango http://www.banrepcultural.org/blaavirtual/revistas/revanuario/ancolh I5/ indice.htm.

Bejarano, Jesús Antonio. El régimen agrario de la economía exportadora a la economía industrial. Bogotá: La Carreta. 1979.

Carmagnani, Marcelo. Estado y sociedad en América Latina 1850-1 1930. Barcelona: Critica. 1984.

Cifuentes, Francisco. Introducción al estudio de los procesos culturales. En: Correa, Hernán Darío, Cuellar, Ricardo Alonso (editores). Imágenes y reflexión de la cultura en Colombia. Regiones, ciudades y violencia. Bogotá: Colcultura. 1991.

Colmenares, Germán. La nación y la historia regional en los países andinos 1870-1930. (Material mimeografiado y publicado). Varios: selección de textos. Bogotá, Tercer Mundo, 1998.

Colmenares, Germán. La formación de la economía colonial (I 500- I 740). En: Ocampo, José Antonio (compilador). Historia económica de Colombia. Bogotá: Planeta, Fedesarrollo. 2007.

Groot, Ana María. Sal, caminos y mercaderes. El caso Muisca en el siglo XVI. En: Herrera, Leonor y Cardale de Schrimpff, Marianne (Eds.). Caminos precolombinos. Bogotá: Instituto Colombiano de Antropología e Historia. 2000.

Herrera, Marta. Ordenar para controlar. Ordenamiento espacial y control político en las Llanuras del Caribe y en los Andes Centrales Neogranadinos. Siglo XVIII. Colombia: Academia Colombiana de Historia, Instituto Colombiano de Antropología e Historia. 1999.

Instituto geográfico "Agustín Codazzi", Subdirección investigación y divulgación geográfica, división de investigaciones geográficas sección de Estudio en áreas no polarizadas. Situación y análisis del proceso colonizador en Colombia. Bogotá: Ministerio de Hacienda y Crédito público, IGAC. 1986.

Kalmanovitz, Salomón. Economía y nación, una breve historia de Colombia. Santafé de Bogotá: Tercer Mundo editores. 1995.

Melo, Jorge Orlando. Del federalismo a la Constitución de 1886. En: Nueva Historia de Colombia, t I. Bogotá: Planeta. 1989.

Melo, Jorge Orlando. Las vicisitudes del modelo liberal (1850-1899). En: Ocampo, José Antonio (compilador). Historia económica de Colombia. Bogotá: Planeta, Fedesarrollo. 2007.

Melo, Jorge Orlando. La evolución económica de Colombia, 1830-1 900. En Manual de historia de Colombia. Bogotá: Instituto colombiano de Cultura. 1979.

Montañez Gómez, Gustavo y Delgado Mahecha, Ovidio. Espacio, territorio y región: conceptos básicos para un proyecto nacional. En: Cuadernos de Geografía, Revista del Departamento de Geografía de la Universidad Nacional de Colombia. Vol. VII, N I-2, 1998. 
Montañez Gómez, Gustavo. Razón y pasión del espacio y el territorio. En: (Compilación). Espacio y territorio. Bogotá: Universidad Nacional de Colombia. 200I.

Ocampo, José Antonio. Colombia y la economía mundial 1830-1910. Santafé de Bogotá: Tercer Mundo, Fedesarrollo, Colciencias. 1998.

Ocampo López, Javier. El Federalismo y la hegemonía liberal. En: Historia de Colombia, t 6. Bogotá: Salvat. 1990.

Palacios, Marco. El café en Colombia, 1850-1970. Una historia económica social y política. Bogotá: El Colegio de México, el Ancora editores. 1983.

Ricoeur, Paul. La memoria, la historia, el olvido. Argentina: Fondo de Cultura Económica. 2000.

Safford, Frank. Acerca de las interpretaciones socioeconómicas de la política en la Colombia del siglo XIX. Variaciones sobre un tema. En: Anuario Colombiano de Historia Social y de la Cultura, volumen 13-I4.

Samper, Miguel. Selección de escritos. Bogotá: Editorial y litografía presencia. 1977. Pág. I 18.

Sánchez, Gonzalo. Las ligas campesinas en Colombia. Bogotá: Ediciones Tiempo Presente. 1977.

Sastoque, Edna Carolina. Tabaco, quina y añil en el siglo XIX: Bonanzas efimeras. En: Credencial Historia. № 255. 201 I. [En línea]. Disponible en Biblioteca virtual, Biblioteca Luis Ángel Arango http://www.banrepcultural. org/blaavirtual/revistas/credencial/marzo20 I I/tabaco-quina-anil-siglo-xix

Sevilla Casas, Elías. Procesos regionales en la periferia colombiana de oriente y occidente: aportes desde la historia y la antropología (Material mimeografiado y publicado).

Velandía, Roberto. Historia geopolítica de Cundinamarca, departamento-municipio-inspecciones-departamentos de policía. Bogotá: Imprenta Departamental Antonio Nariño 1971.

Villegas, Jorge. La colonización de vertiente en el siglo XIX. Medellín: Centro de investigaciones económicas, facultad de ciencias económicas, Universidad de Antioquia. 1977. 